\title{
Time-space intensification: Karl Polanyi, the double movement, and global informational capitalism
}

\author{
Seán Ó Riain
}

(C) Springer Science + Business Media B.V. 2006

\begin{abstract}
This article advances the concept of "time-space intensification" as an alternative to existing notions of time-space distanciation, compression and embedding that attempt to capture the restructuring of time and space in contemporary advanced capitalism. This concept suggests time and space are intensified in the contemporary period the social experience of time and space becomes more explicit and more crucial to socioeconomic actors' lives, time and space are mobilized more explicitly in individual and corporate action, and the institutionalization of time and space becomes more politicized. Drawing on Polanyi's concepts of fictitious commodities and the double movement, and developing them through an analysis of work organization and economic development in the Irish software industry, the article argues that the concept of time-space intensification can add significantly to our understanding of key features of the restructuring of the temporal and spatial basis of economic development and work organization.
\end{abstract}

\section{Time, space, and global informational capitalism}

Having long defined the contemporary socio-economic advanced capitalist order in relation to what it is not - Post-Industrial, Post-Fordist, Post-Modern - theorists are increasingly attempting to define the contemporary era in terms of its own central features. One of the most influential among these formulations are those which emphasize the shift from an economy based on the manufacturing of industrial goods by production workers to one based on the design of informational goods and services by knowledge workers (Castells, 1997; Freeman \& Louca, 2002; Jessop, 2000; Reich, 1991). This informational form of capitalism is also linked to socio-spatial change and particularly the rise of a global economy, spanning local and national borders and apparently operating on a planetary scale (Castells, 1997; Giddens, 1991; Reich, 1991). This global informational capitalism is also

S. Ó Riain $(\bowtie)$

Sociology Department, National University of Ireland, Maynooth, Co. Kildare, Ireland

e-mail: sean.oriain@nuim.ie 
characterized by new organizational forms, typically captured under the loose rubric of "network" forms of organization (Freeman \& Louca, 2002).

Techno-economic, socio-spatial, and organizational changes have combined to transform economic life therefore. But the effects go further to, arguably, transform the temporal and spatial basis of economic and social life itself. For some, the contemporary era is characterized by the "death of distance" and new virtual social spaces; for others, these spaces are increasingly controlled by capitalists, while for yet others local and regional spaces have re-emerged as crucial spaces within the global economy. This article explores this contested terrain of the temporal and spatial restructuring of global informational capitalism and advances the concept of "time-space intensification" to attempt to capture the dynamics of contemporary transitions. This concept suggests that, rather than disappearing or persisting unchallenged, time and space are intensified in the contemporary period: the social experience of time and space becomes more explicit and more crucial to socio-economic actors' lives, time and space are mobilized more explicitly in individual and corporate action, and the institutionalization of time and space becomes more politicized. The concept of time-space intensification seeks to integrate two fundamental insights into contemporary capitalist organization - the undoubted intensification of capitalist domination and exploitation together with the protection and re-assertion of industrial and occupational time and space at a variety of spatial scales (the local, regional, transnational, and so on).

The article locates existing perspectives on time-space restructuring within the theoretical lineages of Weber, Marx and Durkheim. It then develops a number of key concepts from the work of Karl Polanyi - including the notions of fictitious commodities and the double movement - to integrate some of the crucial insights of these classical theorists and suggest some of the causes of the dynamics of time-space intensification. Drawing on these concepts from Polanyi, the article argues that the concept of time-space intensification can add significantly to our understanding of key features of the restructuring of the temporal and spatial basis of economic development and work organization.

The argument is developed using evidence from studies of work organization and industrial development in the software industry in Ireland, which grew rapidly through the 1990s, particularly around the capital city, Dublin. The Irish software industry has continued to grow, creating a high-tech region within a network of global flows in and out of similar regions in the US, UK, Israel, India, Taiwan and elsewhere (Saxenian, 2006). Given that software is apparently one of the most "virtual" of industries, it represents a perfect case for analyzing the transformation of time and space.

\section{Understanding time-space restructuring}

In the era after World War II a particular set of relations among state, society, and market was institutionalized internationally, creating a system of relatively stable national economies organized through an international order of "embedded liberalism" (Ruggie, 1982). These economies were tied together through a negotiated regime of multilateral trade but buffered from the full effects of these international markets by institutions limiting trade and capital flows. Within these relatively stable industrialized economies, large oligopolistic firms flourished and promoted bureaucratic organizational hierarchies - reaching down to the level of the work process through job demarcation and control of work rules (Tilly \& Tilly, 1994). 
The national economy and the job within the bureaucratic firm acted as "time-space containers" (Giddens, 1984), institutionalizing a "spatial fix" for capitalism (Harvey, 1989).

The globalization of the economy has consisted in large part of the weakening and even destruction of these institutional buffers between national economies and global markets. States find themselves trying to respond to pressures from local societies and global markets simultaneously without the breathing room previously offered by controls on transnational trade, finance, and production. Labor markets have become "flexible": work organized through teams and projects, and organizational forms shifting toward disaggregated network forms. Time and space are being reconfigured in both economies and work organizations. The challenge is to understand these transformations in a way that links together spatial structures, projects and practices into a processual, rather than a deterministic, account of time-space restructuring (Brenner, 2004).

Reich (1991) argues that new information and communication technologies make it possible and even necessary to reorganize firms into "global webs," and employees into global telecommuters. For Reich these webs operate smoothly, destroying constraints of space and social structure, moving in conjunction with the ever-circling hands of the clocks on the walls of corporate offices around the globe. These arguments echo those of many neoclassical economists, where the global workplace is essentially a "virtual place" where the constraints of space, social organization and local institutional arrangements have been overcome. The politics of the workplace is replaced by a virtual space of knowledge sharing and creation, particularly for "knowledge workers" such as software developers. Space is dis-embedded while control of the labor process is essentially cooperative. Symbolic analysts live within the "culture of real virtuality" (Castells, 1997) where virtual ties are as real as actual ones and the boundaries between the "virtual" and the "real" blur.

Reich's analysis of the process of globalization is compatible with that of Giddens (1991) who argues that globalization occurs through a process of time-space distanciation where time and space are universalized and "lifted out" or made independent of their immediate contexts. For Reich the global workplace is dis-embedded from its temporal and spatial contexts and becomes a "pure" space for communication and innovation among employees. Giddens's analysis casts light on how this is possible. He argues that communication across distance depends upon the existence of expert systems, or systems of knowledge which actors understand and trust (such as the technical language of high-tech industry), and upon symbolic tokens, or media of communication that can serve as coordinating mechanisms for long-distance social relations where social cues and monitoring are absent or opaque (e.g., money).

However, other authors have portrayed a fundamentally different global workplace where "globalism" - whether it be the ability to create virtual connections or to become increasingly mobile across the globe - is distributed unequally. In particular capital is mobile and "virtual" whereas labor is not and therefore capital can dominate the global workplace (Bluestone \& Harrison, 1982; Burawoy, 1985; Shaiken, 1990). Harvey (1989) argues that time and space have not become distanciated as Giddens claims, but that corporations have colonized local spaces and time has annihilated space in a process of time-space compression. Thus, changes in the global workplace put intense pressure on firms but particularly on workers whose space is increasingly dominated by global corporations (Harvey, 1989). Harvey portrays a global workplace where globalization dominates the once autonomous space of the worker and where capital can marshal globalization in its own interests and reproduce hierarchical relations in the workplace. Space is dis-embedded but the unequal nature of this dis-embedding provides managers 
with renewed hierarchical control in the workplace. The global informational economy is no different as corporations assert their control over technological change through shaping the trajectory of research and its goals, and protecting their "intellectual property rights" and monopolies of the means of communication (McChesney, Wood, \& Foster, 1997). Place derives its meaning from capitalist locational competition through the ideology of competitiveness (Cerny, 1995; Le Gales, 2002).

Differ though they may on the degree of capitalist domination over the "space of flows," both of these theories of time-space distanciation and compression agree that globalization is increasingly dis-embedding the globalized economy and workplace from their local contexts. Other theorists have argued however that the demands for increased flexibility and specialized learning actually make embedding the global workplace in local spaces even more critical. Among economists, those who emphasize transaction costs and the social institutions that make transactions efficient, might also be seen as, at least implicitly, arguing for the continuing importance of social spaces for interaction and learning, particularly in the form of "relational contracting" (Williamson, 1985).

Economic geographers have also shown that efficient production and constant innovation require the construction of shared physical spaces where workers can interact and communicate on a face-to-face basis and where shared goals and meanings can be created and maintained (Piore \& Sabel, 1984; Saxenian, 1994; Storper, 1997). Global competitiveness is therefore dependent on increased spatial embeddedness. The local spaces which can achieve this happy state of affairs will be able to buffer themselves somewhat from the demands of globalism because they possess territorially specific and unique institutional and cultural capacities. Global workplaces are deeply embedded in these territorially and temporally specific contexts under a process which I call here time-space embedding.

But these accounts of the organization of software business and work in Ireland leave us with a conundrum. How can we reconcile the insight that the capitalist market produces pressures towards local fragmentation and loss of autonomy with the emphasis on the reconstitution of strong local relations within capitalist exchange in studies of time-space embedding? Mapping the theories more schematically is helpful in posing the dilemma (see Table 1). There are two critical insights at the heart of this debate. The first is that the knowledge economy is just as deeply embedded in social relations and social spaces as previous techno-economic eras. But the implications of this argument are only fully recognized by theorists of time-space embedding. For the other perspectives, while they recognize this embeddedness it is ultimately overwhelmed by either rationalization or capitalist power. The second insight is that the knowledge economy, organized through the capitalist market, is a structure of exploitation and corrosive competition, not simply equal exchange. This is central to arguments regarding time-space compression but is not integrated into the other perspectives. We can then construct a typology of these theories along these two dimensions - the embedding of the knowledge economy within time-space and the structure of the knowledge economy as a structure of exploitation or exchange.

Table 1 Theories of time-space restructuring in contemporary capitalism

Knowledge economy is based on ...

Exchange

Time-space distanciation

Time-space embedding
Exploitation and domination

Time-space compression

Time-space intensification 
The dilemma then is that the two most insightful theories, each of which appears to capture significant elements of the restructuring underway, rely upon quite different basic notions of the capitalist marketplace - either as a dominating force erasing places except as competitive locations or as a relatively benign context for competition based on efficiency. However, we can reconcile both the pressures of the capitalist market and the embedding of "new industrial spaces" (Scott, 1993) without reducing one to the other. There are, of course, examples within existing literature of attempts to do precisely this. Manuel Castells emphasizes the continuing, and even increased, importance of regional economies in a virtual age, but ultimately the "space of flows" triumphs over the "space of places" for Castells (1997). There are more significant tendencies with the work of David Harvey, from within the time-space compression framework, and Michael Piore, whose work on industrial districts I have located within the time-space embedding framework. Harvey's emphasis on the construction of spatial fixities in the accumulation process and on the ongoing tensions between fixities and accumulation is a vital insight (Brenner, 2004; Harvey, 1989). However, Harvey's approach tends to emphasize the ongoing structural dynamics without providing a framework for understanding the micro- and meso-politics of time and space, and the space for political choices that emerges in this tension between accumulation and spatial fixity in capitalism. Michael Piore begins from the fixities of the industrial districts of the "new economy" but also pays explicit attention to the potentially corrosive effects of firms and hierarchies on the social ties of local industrial systems and the public spaces available for social learning (Lester \& Piore, 2004; Piore, 1996).

What the efforts of these analysts show us is that it is crucial to further develop our understanding of the politics of time and space between embedding and compression. The pressures of the market and the embedding of social relations exist in a dynamic and symbiotic tension: the market cannot operate without embedded social relations but unchecked market relations attack those very social relations which sustain them, producing a defense of social cooperation and solidarity on the part of those integrated into the market. These struggles ultimately constitute a contested terrain upon which the future of capitalist restructuring, and the design of new time-space containers, is decided.

There is then a "double movement" between the pressures of time-space compression and the efforts of workers, firms and states to produce new forms of time-space embedding as a protection against these pressures. In the struggle between the two sides of this double movement we find time-space intensification. This occurs in three major ways. First, the experience of time and space is intensified as it is de-normalized with the cracking of the taken for granted time-space containers of nation, corporate hierarchy, and job. As Biggart and Guillen (1999) point out, globalization does not produce homogenization but greater awareness of difference - time and space become more explicit elements of human experience. Second, time and space are themselves mobilized as key elements of strategic action. While all social practices have a spatial and temporal dimension, explicitly spatial and temporal practices become more critical to social and political action as social actors attempt to mobilize time and space strategically within global connections and in protection against the pressures of time-space compression. The "region" becomes a crucial element of economic development policy while "managing the product development cycle" becomes central to information technology firms, and so on. Finally, time and space become highly politicized as struggles take place at multiple levels over the temporal and spatial organization of contemporary capitalism.

Therefore, the concept of time-space intensification is an attempt to reconcile a recognition of relations of exploitation and domination that must always operate through, and be 
transformed by, patterns of socio-spatial embedding. These interactions between exploitation and embedding intensify time with more rapid rates of change in technologies, product markets and organizational structures; increased turbulence, turnover, and mobility in the labor market; the importance of deadlines in work organization; and a revolution in expectations of time and a shortening of time horizons. The intensification of space is not just a matter of the increased importance of face-to-face interaction or of competition between places but of the increasing importance of the ability to mobilize space as a resource in social relations in the face of pressures from the capitalist market. While this mobilization of space can promote competitiveness in the market, it must also be protected from the pressures of marketization which will erode the very social relations upon which it is based. Ultimately, the intensification of space raises, over and over again in concrete social relations, the deep tension between market and society and opens up political spaces for contesting and reconfiguring capitalist social relations.

\section{Studying software in the Republic of Ireland}

Nowhere has this dis-embedding of existing work organization and economic organization been clearer than in the "new" informational industries such as software. This article explores the restructuring of time and space at each of these two levels of one of the newest of these industries - software - in Ireland, where bureaucratic industrial organization had only ever developed to a limited extent. This article explores the dominant interpretations of the restructuring of time and space in informational capitalism through what can only be an illustrative account of the organization of the Irish software industry. This illustrative account draws on two main bodies of research, a study of work organization in a US software company's Irish subsidiary (see Ó Riain, 2000, 2002) and a study of the political economy of the growth of the software industry in Ireland (see Ó Riain, 2004).

To investigate work organization I undertook an ethnographic case study in early 1997 of USTech (a false name used to protect the company's anonymity). The study lasted 3 months and was carried out with the permission and assistance of company management and with the full knowledge of company employees. USTech is well established in Ireland, having located there over 15 years ago and becoming one of the early success stories of Irish industrial policy. For many years it was one of Ireland's primary computer hardware production operations, with a reputation for high quality. The hardware manufacturing operations of USTech Ireland were dismantled with massive layoffs in the early 1990s, leaving local management scrambling for the operation's survival and turning to a complete reliance on the local pool of software skills.

The case study included 12 weeks spent working as a technical writer on a software development team, 20 interviews carried out with engineers and developers working in the company, 15 interviews with company managers, and attendance at 15 team, department, and management meetings (not including team meetings of the team in which I worked). The five long-term members of the team were employed by USTech but were working on a contract designing a product for Womble Software, a spin-off from USTech headquarters in the US. In addition to the team leader, Seamus, there were two permanent (Dan, Conor) and two long-term contract (Jim, Paul) staff. During this time I participated fully in the work of the team and wrote a User Guide for our product which was installed on the system as online help for users of the system. I sat in the same cubicle as the rest of the team, attended team meetings and interacted closely with them on a regular basis on decisions regarding the User Guide. After an initial period of suspicion of my motives, the team members were 
very welcoming and helpful to me. Indeed the regular flow of contract personnel in and out of the team meant that I became a relatively well-established team member.

This study of work organization can be further contextualized through another study of the economic organization of the software industry in Ireland. From 1995 to 2000 approximately 100 interviews were held with managers and executives in indigenous and foreign companies, individuals working in state agencies, universities, technology and innovation centers, industry associations and related industry participants and observers. Irish software grew rapidly in the 1990s and this growth intensified in the late 1990s, with high levels of foreign investment and indigenous firms' exports increasing by $92 \%$ between 1997 and 2000 (Breznitz, 2002). The industry is divided relatively equally in employment terms between foreign and Irish owned firms. Concentrated in a particular region with deep global business and technical ties, the industry is both local and global and cuts across the boundaries of the national economy. Organizationally, firms within the industry have extensive networks with other firms, as do software developers with other technical workers in the region.

\section{Time-space dynamics in Irish software}

The Irish software industry therefore provides a fascinating opportunity to explore these various accounts of the transformation of time and space in contemporary advanced capitalism. This section applies each of the three existing theoretical accounts to the Irish case in turn, while the following section explores an account of time-space intensification in software in more detail.

Time-space distanciation: cracking the time-space containers

The time-space container of the national economy has long cracked in the Republic of Ireland, as the Irish economy was "globalized before globalization." Economic and industrial policy in Ireland shifted dramatically between the mid-1950s and the early 1960s, as protectionist measures were eased for foreign investors, and full integration into the international economy has been the central plank of Irish economic policy ever since.

Across these decades the national territory was remade into a location for investment. The physical territory itself was also remade, particularly when the telecommunications system was upgraded in the early 1980s (Euristix, 1991; Hall, 1993). Trinity College Dublin was also one of the early "backbone" sites for European access to the Internet which meant that (free) access to the Internet came relatively early to some within the Irish industry. In terms both of its technological infrastructure and economic structure, Ireland had become a highly globalized economy. Both in the dark days of the socio-economic decline and the black hole economy of the 1980s and the Celtic Tiger boom of the 1990s it appeared subject to the vagaries of the "space of flows" of international capital (Castells, 1997).

The Irish software industry is characterized by multiple connections to the global economy, as Reich and Castells suggest. Foreign investment has been the main force shaping Irish industrial change over the past four decades, but software has also seen the emergence of a dynamic industry of indigenous firms with extensive global connections. While foreign firms extend locally through sub-supply and research ties, indigenous firms are involved in international business and technology alliances (Ó Riain, 2004). Similarly, while Ireland has a long history of emigration (extending in the 1980s to many technical graduates), the boom of the 1990s saw extensive return migration and, more recently, very significant immigration flows from a wide range of EU and non-EU countries. Flows of business and research 
information through transnational personal and institutional linkages have increased (Saxenian, 2006, p. 358).

Similarly, Womble Software and USTech are interesting examples of the "global web" corporate structure which Reich argues is becoming the norm. USTech's links to the global economy have diversified along with the shift to software services and product development with a proliferation of customers, partners and internal corporate sponsors replacing their previous model of reporting directly to a single office in the US. Formed as a spin-off from a large hierarchical corporation, Womble is partly owned by the four founders, partly by USTech itself, partly by a major customer, and the rest by a venture capital fund in Silicon Valley. It has no more than 15 employees of its own. The development team is based in Ireland and is officially contracted to provide software development services to Womble. The screens for the program are conceptualized by Ramesh, the Vice-President and lead architect of Womble in Cincinnati, but all the development work necessary to turn them into computer graphics is done in a small graphic design house just outside San Francisco. The helpdesk staff which users reach if they call with a problem is staffed by the trained employees of a helpdesk contracting company. The technical writers who write the on-screen help for users are all hired on a contract basis.

In place of more rigid, hierarchical organizational structures we have a shifting web of connections forged into a relatively fleeting alliance. Ramesh himself subscribed to the theory of the virtual economy in a "Thank You" E-mail message he sent to the contract graphic design firm in California:

Our project team was truly an international virtual-team, with up to 8 hours of timezone difference among the different team members. We expected you to work at such a hectic pace, yet, we also demanded extreme flexibility from you in all respects. It is very rare that anybody of your caliber would be able to excel on both these fronts.

These global connections at the level of industry and firm within Irish software suggest, therefore, that there has been a shift from a hierarchical form of organization to a network firm where each team has multiple, different and shifting connections to external partners and customers. The spread of these connections across the globe and the integration of each team into dense sets of local and global networks has cracked the time-space container of the firm and the nation - the expert systems of high-tech and business knowledge and norms and the symbolic tokens of money, certification, and technological experience have created the possibility of much deeper and more sustained social ties across these different territories. The "Irish" software industry is formed out of multiple, shifting global connections.

Time-space compression: subjugating places to the market

However, Irish economic policy to create a "world class" location for mobile investment involved, not only the creation of a "virtual" economy, but also one that facilitated the need of foreign capital. When most national economies were still attempting to negotiate with and control foreign capital, the Irish state turned itself to a relatively unconditional pursuit of such investors - creating the first free trade zone in the world (at Shannon), providing generous tax incentives and grants, a transnational-friendly environment, a young and cooperative labor force and in the 1980s, a world class telecommunications system.

Given the policy emphasis on attracting foreign investment, it is not surprising to find that industrial policy is profoundly shaped by the perceived and stated needs of the foreign multinationals, both those located in Ireland and those that might locate there at some point 
in the future. Debates on raising corporate tax rates have centered, for example, on the impact of raising taxes on foreign investment decisions, and the annual reports of the industrial development agencies place a central emphasis on the factors shaping Ireland's ability to attract foreign investment.

The transformations that followed this political emphasis were far reaching. Irish political and economic institutions were radically reshaped through the 1970s, in large part in pursuit of foreign investment. The structure of state finances has been transformed to greatly reduce taxes on capital and profits in an effort to attract foreign investment, leaving the state heavily reliant on revenues from personal income taxes. The percentage of government revenues from taxes on capital and corporations declined from $2.3 \%$ of GDP in 1965 to $1.2 \%$ in 1985 , while the taxation burden on personal income increased enormously from $4.3 \%$ of GDP in 1965 to $11.4 \%$ in 1985 (OECD, 1997). The education system has been transformed, largely through the creation of a large sector of the third-level education system, which is oriented heavily towards business and technology, and which has in the process transformed the social structure. Furthermore, the ideology of "competitiveness" has been institutionalized as a national policy priority with the establishing of the National Competitiveness Council which monitors almost any aspect of social and economic life for its implications for firm competitiveness. The focus of the competitiveness agenda has been the reduction of costs, and the policy mechanism of choice is increased market competition typically reflected in calls for wage restraint and reduced public spending. Official policy has been in fact to create the national economy as a place that can compete within the global market, and all other policy considerations are to be consistent with this over-riding priority given to locational competitiveness. The "virtual" economy had a capitalist content.

These pressures are also evident in the area of work organization. USTech has its roots in an era where, even in rapidly shifting technology markets, large oligopolistic firms were able to maintain a degree of stability in their environment that enabled them to build stable organizational hierarchies. Even in USTech Ireland, the company had maintained a reputation for job security, good pay, high quality and training (all the while remaining nonunion). But, even if pay and conditions remained good, USTech in the 1990s in Ireland was a fundamentally different firm.

Corporate organization has been transformed with the rise of "markets within hierarchies" as teams now deal directly with their internal and external customers. Getting time to go on training courses or finding funds to pay for new technologies, training, and other infrastructural resources is a common complaint for workers and managers alike. As the USTech Managing Director puts it: "I don't have a budget, it's a customer style relationship within the company and with clients. This has a big impact in that we only provide services that we get paid for. People don't have jobs, they have assignments; these can change every couple of months. There are complaints from some areas, no one is sure who they're working for - I'm saying 'well try and get used to it.' We need to be more able to move people around - we need the flexibility, it's very different from mainframes where you get your production figures at the beginning of the year. Now we have to keep the services very close to demand."

These pressures translate into intense pressures upon workers, as work hours lengthen in the face of looming deadlines:

Conor: We're all tired, we've been at it for two months really. It's a lot of pressure. Something every day. There's no time to take a day and research something. We need a week to go over some of the bigger issues, have some meetings, go over things, you know. There's some dodgy code in there too. 
Among the team members, proposed legislation limiting working hours is discussed ironically:

Séamus: I wonder does Ramesh know about the European Social Charter limiting the working week? 43 hours per week or something.

Conor: Great!

Jim: It's 48

Conor: $\mathrm{F} \# *$ !, that long

Jim: Yeah, 48 for each company, 48 for Womble and 48 for USTech!

Such hours and constant pressure take their toll - the week after the deadline I bumped into Paul on our way in to work:

Paul: I was feeling crap lately 'cause I've been under a lot of pressure and everything.

But now I feel great after having that day off.

As the classic institutions of national economy, hierarchical firm, and demarcated job can no longer contain time and space, the pressures of locational competitiveness in a global market move ever more quickly between product market, regional economy, firm, team, workers, and families. As an international subsidiary, the pressures from the market are all the more intense as the organizational distance - from whatever investment is available at the center - is further, and the specter of locational competitiveness looms large. This reaches even to the team level, where each new project brings the possibility of work being relocated elsewhere. Unions are almost non-existent in the US-owned high-tech companies in Ireland - as the Managing Director points out: "10 years ago USTech in CA was saying "we are non-union or get your ass out of there." As Harvey argues, there are indeed enormous pressures from capitalist markets to compress time and space. The global economy is not simply virtual but also a carrier of the pressures of capitalism.

Time-space embedding: gluing together new time-space containers

Has space simply been annihilated by the pressures of time, therefore? The transformation of space and place is more complex than the story of time-space compression allows (Massey, 1994). Even within these global pressures towards the "hollowing out" of local space in the Irish economy, during the Celtic Tiger years significant transformations occurred in the capabilities of the Irish economy. Spending on research and development increased, new forms of team production were relatively widely adopted, the labor force became increasingly professionalized and productivity improved. Irish owned firms grew and a number became important international firms as exporters and as overseas investors in their own right (Ó Riain, 2004). Most significant were changes in the labor market; as employment rose dramatically, female labor participation increased, unemployment declined, and mass emigration was reversed. As it turns out, these transformations were rooted in new sets of social institutions and alliances between groups within the state and society - not simply in individual entrepreneurial action supported by freewheeling markets for money, labor and technology. If the Celtic Tiger was a mirage, it was also a surprisingly concrete set of changes in economic life - new social and organizational capacities for knowledge creation emerged.

In the mid-1980s, a small software industry had emerged based on ties to foreign firms and fragile local technical communities, formed by the technical graduates and sophisticated users of computing technology who were starting to emerge. Despite a 
massive brain drain, a number of those who stayed started their own companies, combining with a trickle of people from the foreign owned sector and other organizations to form the basis of a fragile set of overlapping technical communities in the 1980s. The industry culture was relatively open in the early years and something of a technical community, linked to international trends, developed - as one developer put it: "There was a lot of swapping of ideas going on from about the mid-1980s on. Anything real that goes on is informal."

In addition, a set of networks, centers, forums, and groups provides an associational infrastructure for information-sharing, cooperation, and innovation in Irish software. This network of associations underpins many of the "relational assets" within the industry (Storper, 1997). A software developer's comments reveal the way that informal associational networks can have an important impact even when not explicitly recognized by the actors involved: "Those industry groups are really just talking shop, they don't have any real impact. But in fairness I suppose I'm being a bit bilious towards them. I do meet a lot of people there. The informal human networks are more important than the formal industry or professional association stuff. Then I'll ring up Michael and say 'what was that tool you were talking about to debug program X? And where would I get it?' So it's good that way. There's a lot that goes on among the people that go there" (Developer/Manager, US TNC doing development in Ireland).

These "powers of association" are also relevant within the workplace itself. The very "virtual teams" that exist in Womble software are rooted in the social relations of workers who are usually located in close proximity to one another, as this allows the team to handle the complex interdependencies between team members through easy and constant communication, and allows them to build a coherent collective identity that becomes the basis of cooperation within the team.

The sheer volumes of information and the dependence of each member of the team on the design decisions of the others make the easy interaction of the team members critical. As Jim at USTech worked on the user interface screens he would intermittently call over to Paul two desks away "what did you call the course number variable, Paul, I can't find it," "are you working on the database at the moment, it's a bit slow," "who's doing the security screens." The questions and answers are discussed on the way to and back from breakfast and lunch.

By contrast, information flows to the United States can be patchy and tend to be limited to broad strategic decisions. A developer in Silicon Valley would have great difficulty in developing this product along with the team around me. Indeed my own easy ability to ask the developers around me for information 15 times a day contrasts with the difficulties I have sharing information with Jane in Silicon Valley, leaving me idle for mornings or afternoons as I wait to be able to call her in the United States to clear up some minor misunderstandings. Where such transnational "virtual" relationships work they are constantly supplemented by travel to meet the team(s) in the other country; e.g., Ramesh was a regular visitor to the USTech Ireland office. This clearly also affected how much employees could learn from their colleagues. The experience of working with the more experienced and skilled developers taught others the skills and tricks which turn a computer science graduate into an effective and innovative programmer.

Located in a city which is attractive to the young people who dominate the software industry, USTech also benefits from access to a large pool of local skilled labor as well as from the connections of the Womble team members to the broader "culture of innovation" within the region. Their high mobility careers are also sustained through social ties to others 
in the industry who can provide the team members with information on job opportunities and can provide formal or informal recommendations to employers regarding the team members' competence. Ease of communication and cooperation ensures that spaces defined by face-to-face interaction remain a critical component of the global workplace, even as virtual spaces proliferate.

\section{Time-space intensification}

Given the evidence that partially supports each of these perspectives, we must therefore return to our conundrum - how to reconcile the pressures of capitalist globalization on particular places with the reassertion of place-based social relations within capitalist innovation itself?

\section{Experiencing time and space}

It should be clear from the above that time and space loom large in the experience of workers, managers and policy makers in the Irish software industry. Where the nation state had been institutionalized as a time-space container, time and space were normalized as aspects of everyday life and political economic conditions. In the limited spatial and temporal cases of the advanced capitalist countries during the postwar "Golden Age" of growth, time and space had receded as elements of these everyday experiences. However, the sources of the new growth within these countries and the new emerging informational economies such as Ireland bring issues of time and space to the fore. Connections to partners, suppliers, customers, and competitors across time zones and thousands of miles were a part of everyday life at USTech and in most firms in the Irish industry. But the experience of time and space had a sharper edge than that.

Managers and policy elites are firmly aware of the shortening of product cycles and the speed of technological and business change. Indeed, many of the mangers and policy makers I interviewed had received MBAs or written theses on precisely these topics, in an attempt to make sense of the new conditions they faced. But the product cycle was important to workers also. As one project ends, the next phase will involve the shift to a Java platform (then the "hot" technology). As the team moves to a new temporal technical phase in the development, this opens a spatial "window of locational opportunity" for Womble Software and the danger that development work could move back to the US or elsewhere. One team meeting discussing the move to Java produced the following exchange:

Michael (Business Manager): We had to get a Java person in Ireland. Ramesh had someone in the US, but we couldn't let that happen, we couldn't let it go there.

Paul: Yeah, you don't want to let the development stuff leak back to the US. If it starts it'll all end up back there eventually.

The Irish team scrambles to gather together Java skills and to give Ramesh the impression that we have more skills than we do.

Awareness of spatial and social difference was also enhanced by globalization (Biggart \& Guillen, 1999). One of the Womble Software managers took us out for a meal when she was visiting from the US. Halfway through the evening I commented to Pat, a contractor, "She seems okay, decent enough," to which Pat replied, "Well, when you come to discover the jungle you have to play with the natives." Workers are also highly aware of competition 
from elsewhere in the world; three members of a different team discuss their Indian boss in the US with Conor and me:

Pat: We have one too - Ranjit

Conor: Ranjit that, sounds like something out of Aladdin

Peter: (Says something imitating Ramesh's accent). That's racist that is (i.e., criticizing himself, very serious about it).

Bob: Yeah, that's an "ism," that is. That's racism.

Pat: They're (Indian software developers) probably over there saying "those bloody Micks."

Aidan: Yeah, saying "drinking pints of Guinness over their computers."

Social and spatial "difference" on a global scale is an everyday part of these software developers' milieu, although it is negotiated within a strong homogenous local culture; awareness of time and space is intensified.

\section{Mobilizing time and space}

Time and space do not simply enter into everyday experience, however. They are mobilized by a variety of socio-economic actors in the global informational workplaces and industries. The demands of global competitiveness are mobilized regularly by managers and policy makers alike, as discussed above. In the workplace, the demands of time are also central. In the work process itself, the mechanism for controlling the software development team is the project deadline. Managerial control over the labor process has shifted from an emphasis on the direct authority of management over work tasks (an authority that in the case of knowledge workers has been steadily undermined) to an increased effort to dominate the workplace through the regulation of time. Through the use of project deadlines, managers set the parameters for the team's efforts.

As it is impossible for the final design specifications to provide solutions to every issue faced by the team, and the actual work done by the team is difficult for management to supervise directly, the deadline becomes the focus of management and team efforts. "Do what needs to be done to get this specification working by the deadline" is the broad task of the team. The deadline is the mechanism by which management brings the intensification of time into the heart of the team. It is also an attractive mechanism of control since direct authority over the work process is undermined by the expertise of the employees and the need for rapid communication and cooperation. In contrast time can be regulated through the use of the deadline with only a limited local managerial presence and with relatively little ongoing exercise of managerial authority. The ability of the firm to enforce time pressures through deadlines is shored up through appeals to the spatial threats of global competition.

Workers respond, however - mobilizing as part of a double movement in the face of efforts to colonize their time, space, and knowledge. They attempt to mobilize around time and to create protections. There are many complaints about deadlines and long hours. Attempts to protect themselves from these pressures largely take the form of strategies to redefine the limits and content of these pressures, rather than outright resistance to the deadlines themselves.

At times, this does take the form of explicitly managing demands on time. Weeks before the project deadline, Conor had told me:

I've a feeling this is the calm before the storm. My attitude when it's calm is get out of here at 4 or 5 'cause when it gets busy... you have to draw the line yourself as far as 
hours go, you have to say once in a while, "Sorry I have something on tonight, I can't stay." You have to keep your standard hours around 39/40. If you let your standard hours go up to 45 then they'll still come to you and ask you to do a few extra hours that evening, they won't think about that extra 6 hours you're doing as part of your standard. It's up to yourself to draw the line.

While the deadline itself took on a sacred and unmovable character, the definition of what counted as "getting finished" before the deadline was a moveable and contested feast. Some issues were left for other, subsequent deadlines. At other times, workers strategized to avoid any extra tasks being given to the team before the deadline. On one occasion Ramesh sent an E-mail about a "work around" the team would have to do around a problem in the database they were using. Not realizing that Dan had been working on this issue for a while now, he set aside a day the week before the release for Dan to work on it.

Jim: Dan will have that done today.

Sean: So what about the day Ramesh is setting aside for it next week?

Jim: Oh God, I'm not going to tell him we already have a solution. He's already

expecting it to slip a bit so if we get it in on time he'll be really happy. I think we're a

little bit ahead of schedule but he thinks we're a bit behind so that suits us.

Space became an asset in handling the politics of time. Having a manager on the other side of the world allows the team, including the team leader, to screen information from Ramesh in order to let the team balance the technical and time demands to their own satisfaction. Having encountered a particularly thorny problem, the team finally found a solution:

Jim: So we're going to do that then. Ramesh never needs to know about it. So we can have it set up the way we want it and he'll have it the way he wants too.

Paul: So we're going to do it the sneaky bastard way

Séamus: I like the sneaky bastard way!

Paul: And Ramesh never needs to know

Séamus: No, no. Well done gentlemen!

Jim: Just don't say anything about this on Monday when Ramesh is here!

In general, team members were careful to protect themselves from undue interference from HQ in the US and left the negotiation of deadlines and larger technical issues to Séamus, the team leader. As Conor advised me when I had sent an E-mail to Ramesh about a problem in the "help" screens:

Conor: Be careful what you send to Ramesh. Cc it to Séamus or better yet send it to Séamus first, let him decide. That's what I do. You have to look after your own behind first you know. I try to get involved as little as possible with Silicon Valley, I give it to Séamus. That way I have a buffer between me and the US.

But workers relied on local spaces beyond the firm as well. The team members maintained contact with their own networks within the industry - at times contacting friends for technical advice and regularly sending bad jokes around email lists of friends. The emergence of "the region" as a critical space for innovation also facilitates mobility as employees find it relatively easy to "job-hop" within the region, and others migrate to the region, attracted by the concentration of high-technology jobs (Saxenian, 1994).

The short-term contract staff members who flitted in and out of the team put a significant amount of work into maintaining their networks, constantly talking on their mobile phones 
about technology, upcoming jobs, and people in the industry. On one occasion, an applicant for a contract position within the team was rejected because one of the team members had worked with him before and had not been impressed.

The region has been mobilized by the state also to support firms. Public investment in education, concentrated for a time on the supply of scientific and technical graduates, played an enormous part in sustaining firms such as USTech. Furthermore, since the 1980s, a network of semi-public institutions had emerged-funded and sponsored by the Irish state and the EU and often linked to the universities-that supported innovation and research. Innovation centers, programs in advanced technology, technology centers, and other institutions were an important collective set of supports for individual technologists and business people (Ó Riain, 2004). These state-supported institutions helped to build interfirm networks, while the middle classes of the technical communities benefited handsomely from the Irish two-tier welfare state (Ó Riain \& O'Connell, 2000). The region and the state picked up at least some of the slack that had been created by the retreat of the institutions of the firm.

\section{Politicizing time and space}

Despite these strategies for self-protection, explicit collective or political action was rare especially in the workplace. The step between protection and resistance is not an automatic one but the intensification of time and space does nevertheless open up time and space for political discussion in a way that had not happened during the period time and space had been embedded within national institutional forms.

We have already seen numerous ways in which the ideologies and practices of competitiveness are used to mobilize time and space in the service of corporate interests. The project of attracting foreign investment resulted, not in the depoliticization of space and territory, but in the hyper-politicization of the national territory as the territory itself became an object of political (and particularly state) action. Reshaping the nation into location through incentives, telecommunications, and regional- and land-use policy, has been a major strategy in the pursuit of mobile investment, a strategy which has drawn the state ever more deeply into the management of space (Brenner, 1998).

But is there a politics that contests these corporate political projects of time and space? At times, workplace dissatisfactions extended into banter about collective action among the USTech employees. When new changes to the computer graphics for the screens arrived 1 week before the deadline the team was furious:

Conor: I'm going on strike.

Sean: That'll make history, the first strike in the software industry.

(Dan laughs ironically)

Conor: You know what last minute changes mean, it means you work your arse off.

Dan: If it's something we've agreed already I'll work my ass off. But if it's last minute changes I won't. It has to be reasonable, or else it's "see you later."

While collective action is dismissed out of hand, the workers hold on to a (poorly articulated) notion of something that is "reasonable," a nascent idea of fairness.

There are also significant local accountabilities among team members, which are much more easily sustained in face-to-face interactions than in "virtual" communications. This can happen even in the most apparently "flat" and non-hierarchical of organizations. I was caught in a bind during a conference call when Ramesh asked me, an untrained technical 
writer with a long and largely irrelevant training in sociology, "Seán, are you happy with the proposal to put the toolbar in the help box?" While I was being formally asked to participate in a design decision, the social structure of this global organization made me think first, not of the implications of my decision for the system itself, but of my loyalties to the developers around me who would be furious at the potential extra work generated by this proposal. Even the periodical visits of Ramesh to Ireland did not solve the problems of miscommunication and alienation felt by the Irish team. As Michael, the business manager of the group, said, "having a remote manager has made getting a process of communication in place a lot more difficult." Problems which would require solution in a face-to-face context can be swept under the carpet or become a figure of fun in a context where communication is by phone and the Internet.

Other local accountabilities to family and non-work lives surface occasionally, as in a conversation before Ramesh arrives in Ireland to take us to a promised celebration dinner:

Jim: Maybe we'll all meet up. I hope he doesn't meet my wife. She has it in for him.

Séamus: Herself and Linda should get together so. They have a lot in common actually - they're both vegetarians too.

Sean: Except when it comes to Ramesh! (Laughter)

Jim: I see you've met my wife!

Despite these complaints and competing logics of social organization, an explicit politics of worker rights is absent. As Aileen O'Carroll (2005) notes in her ethnographic study of work hours among Irish software developers, workers are able to restrict hours in many cases through shaping and imposing local norms but there is no legitimate industry-wide set of norms around the right to limit hours or the demands of the workplace. While there are countervailing pressures, these new workplace institutions have created pressures for longer hours, uncertainty and the boundaries of working life. These are issues that lead these workers directly to a concern with broader issues of social reproduction - the social investments and institutions that support any labor force, and particularly the skilled workers of a knowledge economy. Where large firms have reduced their commitments to individual workers, this creates enormous pressures on workers but also opportunities for creative political movements. There are new issues for workers in knowledge workplaces and new bases for connecting those workplace concerns to broader community, regional, and national political struggles around social investment and welfare supports.

What is particularly striking in the Irish case is that neither time-space compression nor time-space embedding can dominate alone. Ultimately the local social relations need to be protected from the market; when Ireland saw "globalization without localization" in the 1980s - a more pure form of both time-space distanciation and compression - it proved unable to sustain capitalist development (Mjoset, 1992). The local institutions of innovation are designed to serve capitalist purposes but at the same time, if they are to be effective, they must protect the social and public bases of the high-tech region and the system of innovation if they are not to be eroded and local space to be "hollowed out" (Lundvall, Johnson, Andersen, \& Dalum, 2002). This extends further to the subsidies provided to the middle class, including the high-tech workforce, by the "two-tier" Irish welfare state. Ultimately, the embedding of the technical-professional firms and workers of the Irish software industry in social and political institutions opens us a vast range of issues of investment, social reproduction, and equity. Most clearly, it opens up a space of negotiation and struggle over supports for business, but this is the beginning of a debate about reembedding the market as it can be constructed to lead out to these broader issues. Whether 
this debate takes place depends on political mobilization; time-space intensification does not produce a linear political logic but a new terrain of contestation.

\section{Interpreting time-space intensification through Polanyi}

If time-space intensification is a central dynamic in global informational capitalism, how are we to understand its sociological causes and conditions? What are the processes that set these dynamics in train? To examine these questions, we must turn briefly to the theoretical foundations of each of the concepts of time-space restructuring that we have discussed.

Each of the three main concepts in the current literature can be linked (see Table 2) to a specific tradition within the "trinity" of sociological theory - Weber, Marx, and Durkheim. Reich and Giddens's analyses of time-space distanciation are firmly within the Weberian tradition, whereby a cultural logic of rationalization erodes difference, facilitating impersonal administration, exchange, and control but also creating new "iron cages" within which we work. The driving force of temporal and spatial change is, however, rationalization of beliefs and communication, and the outcome is an increasingly globally encompassing world of standardized meanings and symbols.

Harvey's concept of time-space compression is explicitly located within the Marxist tradition, whereby the once autonomous local space of the worker is increasingly dominated by global corporations and the ever more rapid pace of economic life under capitalism. Time annihilates space, melting away "solid" local places into the "air" of the global economy (Berman, 1982). While Harvey makes important contributions to the understanding of spatial restructuring and the emergence of new "spatial fixes" for capitalism (Brenner, 2004), his overarching concept emphasizes the domination of space by capitalism.

I have taken most liberties with the definition of the concept of time-space embedding. Ultimately, this perspective is Durkheimian, as an increased division of labor creates deeper and more complex forms of social integration - although, as for Durkheim, social capital and social institutions are required to play a role in combating tendencies towards fragmentation and individualization. Globalization and informationalism have hastened this process by intensifying the competitive pressures which demand cooperation, by deepening the division of labor and by placing communication around complex and non-standard tasks at the core of economic life. For Durkheim, and for the theorists of "industrial districts," the increasingly complex division of labor produces new forms of solidarity and interdependence.

This article has emphasized the contributions of the Marxist and Durkheimian concepts of compression and embedding and has argued that they are best used in dynamic combination. A promising vehicle for such a synthesis is the work of Karl Polanyi, perhaps the primary source for the sociological analysis of markets. While Marx, Weber, and others

Table 2 Theoretical lineages of concepts of time-space restructuring

\begin{tabular}{llll}
\hline & Knowledge economy is based on ... \\
\cline { 3 - 4 } & Exchange & Exploitation and domination \\
\hline Time-space is ... & Disembedded & Time-space distanciation & Time-space compression \\
& We-embedded & Time-space embedding & MARX \\
& DURKHEIM & Time-space intensification \\
& & POLANYI \\
\hline
\end{tabular}


incorporate markets into their analyses of capitalism and industrialism, Polanyi makes the analysis of the social foundations of market economies, and the threat that unregulated markets pose to "society," central to his explanation of the great political and social transformations if the twentieth century (Block, 2003; Piore, 1996).

Polanyi argues that when markets come to dominate society, they undermine themselves. The problem is not with markets themselves, which have existed throughout history, but with the emerging dominance of an unregulated market in the nineteenth century - a new historical moment. Markets in goods that are produced for sale (cars, toys etc.) are relatively inconsequential for Polanyi's analysis. What concerns Polanyi is the extension of markets to land, money and - particularly - labor. Polanyi argues that labor is nothing other than the human beings of which society consists and to include it in the market mechanism is to subordinate the substance of society itself to the laws of the market. Labor is a fictitious commodity: "Labour is only another name for a human activity which goes with life itself, which in its turn is not produced for sale but for entirely different reasons, nor can that activity be detached from the rest of life, be stored or mobilized" Polanyi (1944[2001]).

Post-industrial economies reach ever deeper into the constituent elements of labor, interaction, and social relations. Crucially, we have seen the increasing commercialization of both knowledge (Castells, 1997) and emotion (Hochschild, 1983). This suggests that we can add knowledge to Polanyi's list of fictitious commodities, as the production of knowledge and the activities of learning and innovation are intrinsic aspects of social action. The knowledge economy is driven by a deep tension between the social relations necessary to generate knowledge (and knowledge as a constituent element of social relations) and the reach of markets into social relations to extract that knowledge, codify it, and commercialize it.

The commodity fiction does serve to help organize actual markets for labor - and now for knowledge. However, neither labor nor knowledge can be marketized unproblematically fictitious commodities being deeply unstable. Marketized labor seeks to protect itself from the depredations of the commodification of human activity itself. The nineteenth century saw a "double movement" of marketization followed by a rash of efforts from all sections of society, seeking to protect themselves from the market. Polanyi's analysis of the "double movement" of the rise of market society and the response of social protection has gained increasing attention in recent years, as a new era of global "market society" emerges. The "double movement" is easily recognized in the project of neo-liberal globalization and the social protections erected through social movements and even some state policies. However, the framework can also provide us with a deeper understanding of the knowledge economy. There is a fundamental tension within the knowledge economy between the marketization of knowledge and the social foundations of its production (Jessop, 2000). But the marketization of knowledge itself faces the challenge of transforming these social practices of knowledge and knowing into defined units of intellectual property. The knowledge economy prompts its own double movement where the marketization of knowledge attacks the social foundations of its production, setting in train a wide range of attempts to protect those foundations.

There is a deep tension within the knowledge economy between the conditions under which knowledge is exploited and the socio-spatial embedding of the social relations of production - the very dimensions outlined in Tables 1 and 2. Polanyi points to both the intimate relationship and intrinsic tension between the exploitative dimension emphasized by Marxists and the social embedding emphasized by Durkheimians. For Polanyi, neither can ever overwhelm the other, and the time-space compression of David Harvey is always met with a myriad of projects of time-space embedding. While they cannot be addressed 
fully here, there are important intellectual connections between Polanyi and both Durkheim and Marx. Polanyi's relationship to Marxism is a checkered one (Block, 2003), but it is clear that there are important points of connection between Polanyi's explanation of the emergence of "social protection" in the face of market society, and the critique of capitalism and the emphasis on civil society in Gramsci and Western Marxism (Burawoy, 2003). Polanyi's own concept of society - as based on an intrinsic human interdependence Polanyi (1944[2001]) and on reciprocity in social relations (Polanyi, 1977) - owes a great deal to a Durkheimian anthropology of "the gift." Polanyi offers, through his analysis of the dynamics of the double movement, a way to bridge what Lockwood (1990) calls Marx's analysis of schism and Durkheim's emphasis on solidarity.

The concept of time-space intensification suggests that at particular moments of increased struggle between compression and embedding, time and space are intensified they become more crucial instruments of labor control, they are mobilized as elements of state economic development strategies, they are experienced as elements of the lived reality of socio-economic life, and they ultimately open up the possibility of new and intensified political struggles that will lead to a re-embedding of time and space in a subsequent historical period.

\section{Conclusion}

The time-space distanciation perspective directs our attention to how every global workplace is shot through with connections to many different places across the world. However, the social world portrayed in such a perspective is one where shared understandings are achieved through universal media of exchange and shared information questions of power, distribution, and negotiation and contestation are difficult to analyze within this framework. Although the perspective rightly emphasizes the fatal cracks in the time-space containers of nation, firm, and job, it tells us little about the social relations within the "space of flows" beyond its basic technological and interactional conditions.

The time-space compression framework addresses some of these problems by showing the pressures placed upon workers in specific global workplaces by the shortening of time in the global economy. However, this perspective sees only domination and cannot theorize the process of contestation in the global workplace nor how certain workers can make significant gains within that workplace. Furthermore, these authors greatly exaggerate the rumors of the death of space and place, as the theorists of what I have called time-space embedding demonstrate. These theorists show how the demands of globalization in fact strengthen the power of place so that specific places emerge to occupy specific nodes in the global workplace. However, these theorists have not been as successful in their efforts to explain how the power of place intersects with these places' global connections nor have they fully addressed how the pressures of globalization manifest themselves in the contestations within these new workplaces.

In the struggle between the symbiotic, but opposing, pressures of time-space compression and the protective efforts of time-space embedding we find time-space intensification. The experience of time and space are intensified as they are de-normalized with the cracking of the taken for granted time-space containers of nation, corporate hierarchy, and job. Time and space are themselves mobilized as key elements of strategic action. While all social practices have a spatial and temporal dimension, explicitly spatial and temporal practices become more critical to social and political action as social actors attempt 
to mobilize time and space in protection against the pressures of time-space compression. Finally, time and space become highly politicized as struggles take place at multiple levels over the temporal and spatial organization of contemporary capitalism. In the Polanyian "double movement" between time-space compression and embedding and between market and society, we find time-space intensification and new possibilities of politics.

E.P. Thompson famously related a new linear and standardized time-discipline to the First Industrial Divide. It may be that Polanyi offers a way into understanding a new timediscipline linked to the Second Industrial Divide. This is a time discipline that is cyclical rather than linear as it is linked to ever more rapid cycles of investment, product development, and project deadlines. It is also "recombinant," as the cracking of the timespace containers of the first industrial divide open a wide variety of temporal and spatial practices and new time-space projects, even within a context of increased power of capital.

Whether this can be sustained or not, Polanyi's framework sits well with contemporary analyses of social change that emphasize such cyclical structural processes - containing particular moments of crisis, contingency, and political opportunity - such as the world systems theory of Arrighi and Silver (2001) and the historical analysis of historical technoeconomic cycles (Freeman \& Louca, 2002; Perez, 2002). These approaches offer a more fruitful road than either linear, determinist accounts of social change or the voluntarism of accounts based in the opposing camps of methodological individualism and postmodernism. As existing forms of time-space embedding are eroded by marketization, we can expect a wide variety of attempts to emerge to create new social spaces where buffers can be erected to protect social relations from the turbulence and corrosion of markets; we might therefore expect time-space intensification to be particularly characteristic of periods of dis- and re-embedding of economic life. To the extent that information technologies increase the speed and distance at which capitalism operates, then it should also be characteristic of informational capitalism.

In fact, we can see Polanyi's double movement at work across multiple time scales and spatial levels - in micro-interactions in the workplace, in meso-institutional spaces, and in the macro-historical transformations that Polanyi himself emphasizes. As marketization reaches into each scale at which informational capitalism is produced, the character of knowledge as a fictitious commodity produces a corresponding range of strategies of social protection. For some, these protections take the form of shielding information from remote managers to make deadlines more manageable, while for others the political issues of social reproduction loom ever larger and they are led to the politicization of time and space.

Extending Polanyi's analysis of fictitious commodities - to recognize knowledge as a fictitious commodity - and of the double movement - to recognize the multiple levels at which the double movement can operate - enables us to understand why time-space intensification is a central feature of global informational capitalism. The intensification of time and space is a matter of the de-normalization of existing patterns of organizing time and space and their increasing significance in everyday life, in strategic mobilization and in politics. Time and space become increasingly matters of strategy and politics for a period of struggle before they become re-embedded. The intensification of time and space is both a period of increased struggle over time-space and a moment of opportunity to re-embed time-space in new forms of social relations.

Polanyi does not explain, nor even suggest any comprehensive explanation of, how these myriad social protectionist responses interact to form the different fascist or social democratic responses to marketization that he documents. However, his concepts of fictitious commodities and the double movement, and the related concept developed here of 
time-space intensification, do suggest that the politics of time and space are more critical and more open than other theories have recognized.

Acknowledgments Many thanks to Fred Block, Neil Brenner, Chris Chase-Dunn, Brian Conway, Mary Corcoran, Michel Peillon, Andrew Schrank, Eamonn Slater, and the Theory and Society Editors for comments and suggestions. Many thanks also to Michael Burawoy and Steve Lopez for discussions on earlier versions of this article.

\section{References}

Arrighi, G., \& Silver, B. (2001). Chaos and governance in the modern world system. Minneapolis, MN: University of Minnesota Press.

Berman, M. (1982). All that is solid melts into air: The experience of modernity. London, UK: Penguin.

Biggart, N., \& Guillen, M. (1999). Developing difference: Social organization and the rise of the auto industries of South Korea, Taiwan, Spain, and Argentina. American Sociological Review, 64, 722-747.

Block, F. (2003). Karl Polanyi and the writing of The Great Transformation. Theory and Society, 32/3, 275306.

Bluestone, B., \& Harrison, B. (1982). The deindustrialization of America. New York, NY: Basic.

Brenner, N. (1998). Global cities, global states: Global city formation and state territorial restructuring in contemporary Europe. Review of International Political Economy, 5/1, 1-37.

Brenner, N. (2004). New state spaces. Oxford: Oxford University Press.

Burawoy, M. (1985). The politics of production. London, UK: Verso.

Burawoy, M. (2003). For a sociological Marxism: The complementary convergence of Antonio Gramsci and Karl Polanyi. Politics and Society, 31/2, 193-261.

Breznitz, D. (2002) Conceiving new industrial systems: The different emergence paths of the hightechnology industry in Israel and Ireland. Science, technology and the economy program working paper series: STE-WP-11-2002. Samuel Neaman Institute for Advanced Studies, Technion: The Israeli Institute of Technology.

Castells, M. (1997). The rise of the network society. Cambridge, MA: Blackwell.

Cerny, P. (1995). Globalization and the changing logic of collective action. International Organization, 49, $595-625$.

Euristix (1991). The impact of communications on industry and industrial development in Ireland. Report to Industrial Policy Review Group, Dublin, Ireland.

Freeman, C., \& Louca, F. (2002). As time goes by: From the industrial revolutions to the information revolution. Oxford: Oxford University Press.

Giddens, A. (1984). The constitution of society. Cambridge, MA: Polity.

Giddens, A. (1991). The consequences of modernity. Oxford: Blackwell.

Hall, E. (1993). The electronic age: Telecommunication in Ireland. Dublin, Ireland: Oak Tree.

Harvey, D. (1989). The condition of postmodernity. Oxford: Blackwell.

Hochschild, A. (1983). The managed heart. Berkeley, CA: University of California Press.

Jessop, B. (2000). The state and the contradictions of the knowledge driven economy. In J. R. Bryson, P. W. Daniels, N. D. Henry, \& J. Pollard (Eds.), Knowledge, space, economy. London, UK: Routledge.

Le Gales, P. (2002). European cities. Oxford: Oxford University Press.

Lester, R., \& Piore, M. (2004). Innovation: The missing dimension. Cambridge, MA: Harvard University Press.

Lockwood, D. (1990). Schism and solidarity. Oxford: Clarendon.

Lundvall, B. A., Johnson, B., Andersen, E. S., \& Dalum, B. (2002). National systems of production, innovation and competence building. Research Policy, 31/2, 213-231.

Massey, D. (1994). Space, Place and Gender. Cambridge: Polity Press.

McChesney, R., Wood, E. M., \& Foster, J. B. (Eds.) (1997). Capitalism and the information age. New York, NY: Monthly Review.

Mjoset, L. (1992). The Irish economy in a comparative institutional perspective. National Economic and Social Council Report no. 93. Dublin, Ireland: NESC.

O'Carroll, A. (2005). The long and the short: Working hours in the IT sector in Ireland. In G. Boucher \& G. Collins (Eds.). The new world of work. Dublin: Liffey Press. 
OECD (1997). Information technology outlook 1996. Paris, France: OECD.

Ó Riain, S. (2000). Net-working for a living: Irish software developers in the global workplace. In M. Burawoy et al. (Eds.), Global ethnography. Berkeley, CA: University of California Press.

Ó Riain, S. (2002). High-tech communities: Better work or just more work?. Context, 1/4, 36-41.

Ó Riain, S. (2004). The politics of high tech growth. Cambridge, MA: Cambridge University Press.

Ó Riain, S., \& O'Connell P. (2000). The role of the state in growth and welfare, chapter 16. In B. Nolan, P. O'Connell \& C. Whelan (Eds.). Bust to boom? The irish experience of growth and inequality. Economic and Social Research Institute/Institute for Public Administration, Dublin.

Perez, C. (2002). Technological revolutions and financial capital: The dynamics of bubbles and golden ages. Cheltenham, UK: Edward Elgar.

Piore, M. (1996). Review of the handbook of economic sociology. Journal of Economic Literature, 34, 741754.

Piore, M., \& Sabel, C. (1984). The second industrial divide. New York, NY: Basic.

Polanyi, K. (1944[2001]). The great transformation. Boston, MA: Beacon.

Polanyi, K. (1977). The livelihood of man. New York, NY: Academic.

Reich, R. (1991). The work of nations. New York, NY: Vintage.

Ruggie, J. G. (1982). International regimes, transactions and change: Embedded liberalism in the postwar economic order. International Organization, 36, 379-415.

Saxenian, A. (1994). Regional advantage: Culture and competition in silicon valley and route 128. Cambridge, MA: Harvard University Press.

Saxenian, A. (2006). The new argonauts. Cambridge, MA: Harvard University Press.

Scott, A. J. (1993). Technopolis. Berkeley, CA: University of California Press.

Shaiken, H. (1990). Mexico in the global economy. San Diego, CA: Center for US-Mexican Studies.

Storper, M. (1997). The regional world: Territorial development in a global economy. London, UK: Guilford.

Tilly, C., \& Tilly, C. (1994). Work and labour markets. Handbook of economic sociology. Princeton: Russell Sage.

Williamson, O. (1985). The economic institutions of capitalism: Firms, markets, relational contracting. New York, NY: Free Press.

Seán Ó Riain is Professor of Sociology at the National University of Ireland, Maynooth. He is the author of The Politics of High Tech Growth (2004) and co-author of Global Ethnography (2000). Current research projects include: (1) the emergence of a global system of work and employment through the transnational ties between Silicon Valley and Ireland (with Chris Benner); (2) a life history study of social change in twentieth-century Ireland (with Jane Gray and others); (3) the politics of the global informational economy (including articles on the evolution of the computer industry, technology-driven commodity chains, the role of the "developmental network state" in developing "global regions" in high tech); and (4) the methodological issues raised by ethnographic studies of global processes. 